\title{
La escritura como pretexto autobiográfico: Adolfo Vienrich
}

\author{
Gonzalo Espino Relucé \\ Departamento Académico de Literatura
}

\section{Pretextos}

La ausencia de una autobiografía de Adolfo Vienrich (1867-1908) que esboce el autorretrato donde podamos mirar la autocomprensión del autor, tal cual se habría imaginado el escritor, es desde ya un primer escollo para la indagación autobiográfica en el espacio đe la escritura. Dicha omisión tiene que ver con el sentido colectivo que adscriben las opciones políticas que emergen a fines del XIX con el radicalismo anarquista que salta a la escena nacional. En términos globales se traduce en compromiso social y actitud ética de quienes encabezan esta corriente ante la sociedad peruana. De modo que la ausencia de una imagen que haga expresa el «yo» en el ámbito de la escritura está ompensada con las acciones del individuo convertido ahora en sujeto de la escritura que aspira hablar desde una postura colectiva de la que se siente parte el autor. "Jorge Puccinelli Converso"

La vida de Adolfo Vienrich podría estar sintetizada más o menos así: hijo de un comerciante alemán y de una señora principal de Tarma, inicia su tránsito escolar por los colegios mayores San Ramón, de su lugar natal y luego, ya en Lima, en el Colegio Guadalupe. La Universidad de San Marcos, donde estudia Ciencias, se revela como momento crucial en la historia de nuestro personaje: empieza la resolución de su conflicto de identidad al optar por el radicalismo y participar de la fundación de la Unión Nacional que encaminó don Manuel González Prada, y simultáneamente, su escritura inicial expresa conocimiento de la otra república de indios, así lo podemos observar en su tesis de Bachiller El aliso peruano (1888). A la muerte de su padre retorna a Tarma. Su vida transcurre entre la Farmacia «El Progreso», la acción pedagógica, la participación en varias lides electorales y la difusión de las ideas radicales en La Aurora 
de Tarma; la publicación de un conjunto de texto escolares, pero sobre todo un ciclo escritural encaminado a revelar el genio y cultura de los indios: Tarmap Pacha-Huaray (1905) y Tamapap Pachahuarainin (1906)'. Historia que culmina con el suicidio del autor en 1908.

A partir de esta apretada síntesis biográfica, planteó indagar el rol que cumple la vida del autor entendida como la resolución de las tensiones que se producen en la escena social en el que se desenvuelve y en las escisiones culturales para definir la personalidad de nuestro sujeto. Dicho de otro modo, y acá recupero una tesis básica de la perspectiva marxista, son las condiciones sociales las que determinan al sujeto; mejor, digámoslo, en la escritura de La ideología alemana: «No es la conciencia la que determina la vida, sino la vida la que determina la conciencia» (Marx-Engels 1968: 55). Y por sujeto estoy entendiendo la definición de una individualidad en relación a una tradición, conflictuada o no, desde la realidad real y ésta tiene que ver con su resolución en términos de adhesión o no. Lo que eonstituye la representación de una subjetividad que siendo individual establece así misma una subjetividad colectiva. Esta conformación está marcada por la historia de la realidad, visión de época o momentos límites y en lasque indiyiduos conflictuados por una situación concreta de pertenencia y no-pertenencia logran unificarse en esa conciencia, esto es en sujetos. En cuanto se trâta de observar cómo la autobiografía, sin ser espejo, ni reflejo (para desentendernos de algunos vicios comunes de las corrientes ortodoxas), participa en lacenformacióndel texto, mejor todavía armoniza sus conflictos terrenalos eniunåreschituranuelaparece como «equilibrio inestable». Dicha conformación tendría que ver con la siguiente hipótesis: el individuo ejercita un conjunto de operaciones, conflictuales o no, al convertirse en sujeto. Al hacerlo se ve involucrado, muy a pesar suyo, en condiciones predeterminadas que evocan tradiciones y rituales, adhesiones y rechazos, con las que el individuo no siempre coincide. La conformación material del sujeto esgrime los signos que van a ser representados y reinterpretados en el espacio de la escritura.

Metodológicamente voy a entrar a un campo en el que hay que andar con mucho cuidado, por lo que alguien podría estar pensando equivalencias (equiparar realidad social con realidad escritural) que nuestra perspectiva marxista

1 En adelante, cito a Tarmap Pacha-Huaray/Azucenas quechua (1905) y Tamapap Pachaluarainin/Fabulas quechutas (1906) con las abreviaturas TPH y TP respectivamente. 
no reclama y para no caer en una suerte de traición a «La biografía oculta» de Adolfo Vienrich, habrá que recordar Alfonso Reyes (1952: 111):

En el campo de la investigación literaria, nada requiere un pulso más delicado y una experiencia mayor del método crítico que el averiguar la dosis de autobiografía que llega hasta las obras de un escritor. El tomar al pie de la letra cierta declaración en primera persona puede conducir a los peores extremos. El "yo" es mucha veces un mero recurso retórico. Los recuerdos de la propia vida, el transfundirse en la creación poética, se transfiguran en forma que es difícil rastrearle la huella. En ocasiones, los testimonios más directos se esconden detrás de un párrafo que sólo contiene, en apariencia, ideas y conceptos abstractos. En ocasiones, lo que se ofrece como una vocación de hechos reales puede ser un mero efecto de inventiva literaria.

Andar con reservas y dudas dado que el propio espacio de la escritura las reproduce; del mismo modo, la evideneía de algunos signos en términos de contenidos dan cuentan de otros espacios de fas respuestas cuya autobiografía que exploraré a continuación.

\section{Biografia de la escisistónio teca de Letras}

La aplicación de "Ta leses marxista "son fos hombres los que hacen la historia y la determinan» tiene que ver acá con el proceso y tradición en que el autor se instala ante el devenir de su propia historia (de individuo a sujeto):

Somos nosotros mismos quienes hacemos nuestra historia, pero la hacemos, en primer lugar, con arreglo a premisas y condiciones muy concretas. Entre ellas son las económicas las que deciden en última instancia. Pero también desempeñan su papel, aunque no son decisivas, las condiciones políticas, y hasta la tradición, que merodea como un duende en las cabezas de los hombres. (Carta F. Engels a Joseph Bloch, 21 set. 1890. Marx-Engels 1968: 72).

Esta historia está signada por la representación de un escenario de desencuentros cuyos resultados será la ausencia de una identidad común por adscribir. El nacimiento de Adolfo Vienrich, ocurrida el 12 de noviembre de 1867, tiene aquella aura de lo indefinido: un mestizo ${ }^{2}$ que no asume por completo el imaginario alemán ni la significación de casta del apellido De la Canal, produ- 
ciéndose a la larga un vacío en la definición de la pertenencia, como se quiere en el lenguaje marxista, la «adhesión» como forma de pertenencia que ocupa el enfrentamiento de la juventud. El descubrimiento del indio va a llenar ese vacío.

El mundo del padre, don Adolfo Vienrich Bünter (Berlín 1825-Tarma 1897) estará representando la cultura de occidente, lo «universal» (desde la cual se puede ignorar y ejercitar negaciones) y, simultáneamente, la imagen del poder que de por sí da ubicarse en el comercio. La madre, doña Concepción de la Canal García (Tarma 1847-1934) por su inserción en el campo de los «principales» (mundo de espalda o rodeado, inevitablemente, del mundo indígena) y por su pertenencia al espacio de la provincia (el mundo del atraso próxima a los indios) resulta doblemente conflictual para el imaginario del joven Vienrich. Nacido en este clima de contradicciones, ante un mundo prácticamente escindido, para el autor, se vuelve obsesiva la pregunta sobre su identidad cultural, de modo que el espacio de la escritura puede mirarse como una tentativa de respuesta a sus interrogantes.

La máscara va a ser una forma de expresiôn de un colectivo que todavía no cobra vida, que se manifiesta en los seudónimos que utilizará como una suerte de distanciamiento entre lo que se escribe y desde dónde se escribe (o en respuesta a qué se escribe). Julio Noriega recuerda que en el caso de los escritores de literatura quechiug el seudóname censtituye angáscara del sujeto productor cuya marca es la ambigiedad. "Es puente entre, dos mundos encontrados»; por lo que el seudónimo le sirve "para legitimar su producción» y desde otra perspectiva, «para esconder su identidad individual» (Noriega 1993: 38). En Adolfo Vienrich se produce esta opción por los seudónimos: se llama a sí mismo: Unos parias, Pumacahua, Cahuide con lo que "se convierte en voz colectiva» que «intenta» su inserción en el mundo indígena y simultáneamente aparece como referente, o como quiere Julio Noriega (1993: 39), es recibido por la cultura occidental «como indígena»:

Con la adopción de un segundo nombre quechua el sujeto se desdobla, sin dejar de ser el mismo individuo mestizo, en otro de filiación indígena. Este otro realiza dos operaciones complejas con relación al mundo quechua: reingresa a la comunidad indígena y se apropia

: Estoy utilizando la categoría mestizo en el sentido usado por el Inca Garcilaso. Enrique Carrillo, Cabotín. llama a Adolfo Vienrich indogermano. (Cf. Puccinelli 1945). 
de la escritura. $\mathrm{Al}$ incorparse a su pueblo se socializa, se convierte en voz colectiva, autorizada, legítima y representativa de ese pueblo. Este criterio de autenticidad y legitimidad también lo transmite al mundo occidental, que lo recibe como indígena. A su vez, al valerse del signo gráfico para su creación -creación del pueblo-, se apodera de un medio de expresión artística en nombre suyo y en el de la colectividad a la que pertenece.

Si bien en líneas generales esto opera así, hay que reparar que dicha tradición en la autobiografía de nuestro autor revela una opción que está encaminada a reconocerse, efectivamente, como "voz colectiva» e indígena, pero esta voz inclusiva recuerda, por los propios seudónimos utilizados, a otros segmentos sociales desde las prácticas radicales, anarquistas (artesanos y obreros), así por lo menos revela el seudónimo «Unos parias» (curiosamente indeterminado: no son «los» ni «el», remeda por el contrario a una colectividad que enuncia un texto). Tampoco puede olvidarse que el seudónimo se vincula a una edición que circula entre artesanos y obreros, me refiero a Los Parias (1904-1911). De otro, los seudónimos están operando como denotación de una opción que homogeniza las voces indígenas y contestarias al utilizar el seudónimo «Pumacahua» $y$ «Cahuide». El caso de «Pumacahua» resulta sintomático, esboza el tránsito de un comportamiento en el que la lealtad a la corona es evidente (participar del ejército realista en el momento de la gesta tupacamarista)

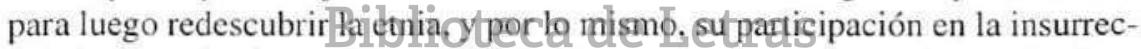
ción independentista def Sur y yCahuidep que come se recuerda, es el primer indígena imaginado que organiza una rebelión.

Esta biografía escindida tiene que ver con la situación dramática que ocurre en el ámbito del imaginario colectivo del país en plena Guerra del Pacífico. La idea de situación límite y país inviable, luego de la guerra, califica adecuadamente la urgencia de reconstrucción del Perú; su imagen, en el ámbito de la realidad, de la historia, supuso el balance de los roles cumplidos por blancos e indios, y entre éstos los sentidos de pertenencia, o mejor aún, la evidencia de un segmento social mayoritario. Manuel González Prada, sintetiza bien el problema en el «Discurso en el Politeama»: «No forman el verdadero Perú las agrupaciones de criollos y estranjeros que habitan la faja de tierra situada entre el Pacífico i los Andes; la nación está formada por las muchedumbres de indios diseminada en la banda oriental de la cordillera.» (González Prada 1985: 89). Esta lectura se va a traducir años más tarde en una propuesta ordenadora en el Programa de la Unión Nacional. (Esta historia también se va elaborando en función de un doble tránsito: de alumno que está en continuo aprendizaje de 
sus maestros y de profesor que establece una dinámica relación con sus alumnos. Estudiante primero en una escuela local, diremos en olor a provincia; su traslado al Colegio Guadalupe de Lima, suerte de desarraigo del mundo provinciano. Luego, docente en la capital y su posterior retorno a Tarma, que implica aprehensión de un mundo que plantea al autor creatividad e ingenio ante un conjunto de interrogantes. No existen materiales educativos, ni pedagogías adecuadas dado el atraso que significa la provincia; él mismo será parte de la resolución de esta problemática al elaborar varios libros de textos, entre los más significativos el Silabario tarmeño $(1904)^{3}$. Es en la Universidad de San Marcos que Adolfo Vienrich se vincula a una intelectualidad de avanzada, en mayo 1891 lo vamos a ver firmando el acta de fundación (Una temprana muestra es su investigación de tesis, para el cual elige un árbol de nuestra serranía: El aliso peruano, sustentada e inmediatamente publicada en 1888). Desde entonces, su vida tiene que ver con el ideario radical y anarquista; como tal participa como integrante del Comité de Tarma, será representante político, inaugura la Escuela de Oficios en 1905 y 1907, regenta el municipio local, precisamente los conflictos que le crean su adversarios configuranano de los móviles de su suicidio ocurrido el 27 de setiembre de 1908.

Contextualizado también por la preocupación socio-cultural que se produce en torno al indio desde distintas perspectivas (educación, legislación, etc.) a fines del XIX. Sobre todo el impacto de las opciones escriturales por el indio, al respecto cabe mencionar lagmportanciade lapoesía indigenistas que culti-

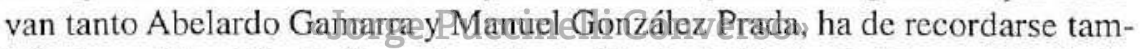
bién la publicación de Aves sin nido de Clorinda Matto de Turner. Abelardo Gamarra, en la década del ' 70 estará publicando sus poemas, escribe bajo la influencia de los sucesos de Huancané, despojo de tierras y exterminio de indios (1866-1877), denuncia el maltrato que viven los niños indígenas en "Los cholitos ${ }^{4} \mathrm{e}$ inicia una cruzada a favor de estos. Lo propio ocurre con Manuel González Prada durante 1871-1879 que parcialmente publica y que más tarde Luis Alberto Sánchez ha llamado Baladas peruanas. No está demás recordar la reflexión indigenista desde el ya citado «Discurso en el Politeama (1888), a una

3. Sobre la propuesta pedagógica. Ferrer Broncano ha realizado un estudio inicial y suficiente para dar cuenta de los aportes a la educación peruana, especialmente en medio rural. Véase: FERRER BRONCANO, Joaquín, La labor educativa de Don Adolfo Vienrich en la Provincia de Tarma. Lima, Universidad Nacional Mayor de San Marcos, 1957 (Tesis para optar el Título de Profesor de Segunda Enseñanza/ Facultad de Educación). Publicado con el mismo título: Tarma. Lib. Imp. La Aurora. 1959: 77 p.

4 Cf. "Los cholitos" en En la ciudad de Pelagatos. (2a. ed. Selección, prólogo y nota bio-bibliográfica de Edmundo Cornejo U. (Lima, Ediciones, Peisa, 1973), pp. 128-130. 
definición social como en «La cuestión indígena» (1905) y «El problema indígena» (1906) que vieron luz en Los parias, mediando entre éstas la publicación póstuma de «Nuestros indios» (1904).

\section{Escritura: representación autobiográfica}

Como hombre de la ilustración escribe en castellano, pero como mestizo asume una vocación de búsqueda por armonizar su vida en una lengua eclosionada que intenta representar al indio a pesar de qué éste no sea objetivamente el lector de su escritura, aunque, simultáneamente, su escritura implica ruptura con el sistema al no corresponder a la norma. El problema da para más, la armonía lograda en el nivel de la escritura va a ser siempre de ese «equilibrio inestable» del que nos hablaban los formalistas rusos. La propia lengua vernácula, a pesar de la diversidad y riqueza de la recopilaciones ejercitada por Adolfo Vienrich, se homogeniza en una escritura que no siempre transa con el quechua señorial del Cuzco. En buena cuenta la escritura es un intento de armonizar la problemática del sujeto: básicamente diremos, se armoniza en términos de bilingüismo, aunque podría extrapolar la tesis de que los lectores virtuales corresponden al circuito ácrata de Los Parias.

La indeterminación desde el sujeto de la escritura en un «nosotros» que suplanta al «yo», o la casitotal auseneia de la primerapersona en la enuncia-

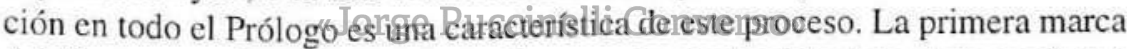
del discurso es elocuente respecto al comportamiento del sujeto de la escritura:

Causa profunda pena el desconocimiento i la ignorancia en que vivimos respecto de la literatura incaica, pues las pocas obras i fragmentos conservados no[s] bastan [par]a enseñarnos el pasado glorioso de esta noble raza quechua. Sin embargo estos fragmentos mutilados nos hablan de una grandeza incomparable i suplen a los monumentos destruidos i al silencio de los historiadores.

Aunque muchos niegan la existencia de tales manifestaciones [...]. (TPH: II; énfasis mío).

Podríamos suponer que la enunciación interactúa desde un «yo» que se explícita en un «nosotros» tal como ocurre en las líneas citadas. No es solamente «Causa profunda pena», sino "[A mi me $]. . . »$, la primera enunciación discursiva habla desde la perspectiva en la que el sujeto está determinando su propia forma de ser, está suponiendo el impacto de una situación en su vida por eso su 
extrañeza ante «el desconocimiento i la ignorancia». Más aún, tal singularidad no es patrimonio de un individuo, sino de una colectividad en la que más adelante se ubicará e autor para la enunciación total del texto; tal colectividad está representada acá por ese «nosotros». Esta suerte colectiva del sujeto de enunciación deja de ser implícito para expresar abiertamente «no[s] bastan [a nosotros par]a enseñarnos el pasado glorioso», que, casi inmediatamente se traduce en «el desconocimiento i la ignorancia en que vivimos». Luego se expresa en relación a la cultura indígena que estudia, ya no sólo como objeto que valora sino también como reconocimiento al sujeto que produce dicha cultura. Se escribe desde la primera persona plural, colectiva, en consecuencia, desde un imaginado sujeto plı ral cuya correspondencia social está en ese «nosotros» que descubriremos más arde como los «verdaderos peruanos», que el autor sintetiza en el indio, fuente de una historia por realizar. Visto así, está representando, teóricamente, a estos mestizos que han roto con los «encastados $»^{5}$. Explica, desde ya, el tipo de adhesiones queVienrich comparte con la cultura de indios y que marcan sus propias simpatias. Esto aparece como reconocimiento de una cultura llamada «literatura incaica» y definida como pertenencia de la «noble raza quechua» cuya grandeza es «incomparable». Si bien la lectura está vinculada a lo que se hereda, es decir, al pasado de estos "peruanos", el tiempo fundacional se instala en el «ahora» que nos deja entreleer en su escritura y que reclama la posibilidad de un texto o varies textos que suministren o postulen identidad para los peruanos ( $\mathrm{Cf}_{4} \mathrm{TPH}_{\mathrm{C}} \mathrm{CXII}$ ). El reconocimiento del indio implica inmediatamente la presencia del sujeto detractor (invasor-español) que sólo ha desbastado el espaero andifino, a diferencia dés que ocurre con el otro (invadido-indio) de que quien proyecta elementos constructivos. El sujeto detractor se manifiesta'desde las primeras líneas del Prólogo como agente de censuras, mutilaciones ý/o destrucciones, obra negando y excluyendo; en la escritura («los historiadores») ejercitan el «silencio» o niegan «la existencia» de la cultura quechua. Este silencio, esta negación, los estragos de estas operaciones corresponden en el pasado a españoles y frailes; en el presente a la nueva guerra civilizadora que se traduce en modernización y que el tarmeño ironiza así: «Hoi... ya no se juega [Huin hui...] por que dicen nos estamos civilizando (!!)»(TPH: XLVIII).

Uso esta categoría en el sentido que construye don Manuel en aNuestros indios w: EEl verdadero tirano de las masas. se vale de unos indios para esquilmar y oprimir a los otros es el encastado, comprendiéndose en esa palabra tanto al cholo de la sierra o mestizo como al mulato i al zambo de la costa [...] la población se divide en dos facciones mui desiguales por la cantidad: los encastados o dominadores y los indigenas o dominados.n (Gonzílez Prada 1908/1972: 134). 
En efecto, el director de La Aurora de Tarma define su identidad desde una perspectiva que da consistencia a su actitud vital y es coherente con lo que piensa en tanto definición social del país. No en vano el «nosotros» desde el que habla Vienrich representa la pertenencia presupuestada por la máscara de los seudónimos. Y la hace extensiva a artesanos, obreros y mestizos descastados como él (en realidad, podría decirse, que está hablando desde un lenguaje acrático). Como huella de la escritura plantea la armonización del conflicto individual en el conflicto social, resuelve su identidad en la imagen del indio como representación del Perú. Una segunda forma de escritura en que puede advertirse la huella autobiográfica la encontramos en la recurrencia a un pasaje sobre el Inca Garcilaso de la Vega. El Inca para Adolfo Vienrich resulta paradigmático toda vez que le da las «herramientas» necesarias para resolver su propia problemática. No es ya el discurso social que adscribe como anarquista sino la metáfora ejemplificadora de la vida del Inca resuelta en la escritura. Hay una suerte de paralelismo que no sê enuncia, pero que podría leerse en el texto que elabora y recoge Vienfich respeeto a Garcilaso. Esta inclusión marcada por la simpatía, se inicia cuando alude a la suerte que corrieron los indios con la llegada de los españoles: «no debe extrañar la coacción ejercida para toda libertad; pues se dejaba sentir hasta para la publicaciones en lengua indígena a pesar de los clamores del mestizo Garcilazo" (TPH: XXII); el Inca aparece como el primer defensor de fa lengua y él, al igual que Garcilaso, se está definiendo como mestizo:

\section{Biblioteca de Letras}

A los hijos «esespañol cienindiac8 de indio, i de española, nos llaman mestizos por decir que somos mezclados de ambas naciones: fué impuesto por los primeros españoles, que tuvieron hijos en indias, i por ser nombre impuesto por nuestros padres i por su significación me lo llamo yo a boca llena i me honro con él. Aunque en Indias, si a uno de ellos le dicen, sois un mestizo, o es un mestizo, lo toman por menosprecio. (Garcilaso de la Vega [1609] 1985: 416).

Para Vienrich la oferta del Inca tiene sentido toda vez que esta imagen prefigura una solución armoniosa a su conflicto de identidad. No sólo se resuelve en términos biológicos; lo hace también, en términos de escritura. El Inca resulta el primer defensor de la «raza», realiza la mejor defensa de la lengua andina; Garcilaso reconstruye ese imaginario indígena del que habla Vienrich. Reconoce en el texto del Inca Garcilaso «las grandezas del Perú», de suerte que resulta «el cuadro más rico en pormenores, más brillante, más animado» del Perú anterior a la Conquista y de lo que se ha perdido: «Ha sido y será siempre 
uno de los escritores más populares». El Inca Garcilaso se convierte en símbolo para nuestro autor. El autor de Tarma Pachahuarainin está tratando de hacer lo propio con su obra al ofrecer una imagen de la cultura y la historia de los indios en el Perú, y al hacerlo quiere también trazarlo con esa «sencillez de estilo» caro propósito que está en el lugar del deseo y, en tanto propuesta, «comunica al lector la fé, que le inspira calurosamente» Vienrich va proponer que su discurso sea inevitablemente propaganda. Para fines del XIX no es sólo escritura sino prédica y acción de acuerdo al ideal radical; su escritura se traduce en la defensa de la lengua (dejar fijada la existencia de una lengua disponible para el arte literario, pero sobre todo dar muestras de la cultura oral que pervive al oprobio de la colonia; la de los indios, diremos para Vienrich).

El texto como escritura autobiográfica podría examinarse a través de sus adhesiones lingüísticas. Si bien hay un tópico común en la escritura que lo vincula al radicalismo anarquista de Manuel González Prada, este opera desde dos perspectiva: a nivel de la escritura, es decir, en la forma como se fija el texto y sobre lo que se piensa en relación al idioma. Desde la perspectiva del radicalismo, la reflexión sobre el idioma no resulta monolítica hay, diríamos, diferencias sobre los idiomas regionales y sobre la posibilidades de una lengua de transacción universal en tanto el francés, el alemán, el inglés y el español se condensen. Incluso el propio mentor del radicalismo anarquista, don Manuel González Prada oscila entre una propuesta que rechaza los idiomas regionales ( $«$ En el idioma s'encasilla eBñesqueino espiziturde nacionalidad. Cada pueblo admira en su lengua el non plus ultra de la perfeccién i se imajina que los demás tartamudean una tosca jerga.» (1894/1985: 262)). Desde la óptica de una escritura en español americano podríamos decir que, primero, se la reconoce como impuesta y dominante, como una representación segmentada del poder en la vida social: los blanco hablan español, indios se restringen al quechua. Y segundo, se formula o reflexiona en torno a esta relación, su utilidad y alternancia social a través de las diversas apropiaciones que ejercitan los usuarios de esa lengua. El propósito de una escritura en español americano resulta una suerte oferta inevitable para el escritor: «Las lenguas aborígenes de América nos han previsto de mil palabras nuevas y expresivas.» (González Prada 1886: 43). El español americano, para efectos prácticos se resuelve también en la forma como se fija la escritura; por lo que encontramos un terreno coincidente en el que la lengua es el escenario de reproducción también de esa compleja identidad en conflicto. La escritura de Vienrich va a estar poblada y fijada como lengua hablada desde la perspectiva americanista: g por j, ex por es, y la i latina por la y griega, etc. El español americano, y su fijación escritural, participan como respuesta a 
la problemática de una evocación autobiográfica: la lengua dominante es, de por sí, espacio de exclusión. Siendo así, el español americano será un recurso de conciliación, por lo mismo, metafóricamente, representa la apropiación de dicho sistema por los mestizos. El español americano va a ser espacio de la apropiación de la cultura del otro, terreno sin conflictualidad para su expresión y comunicación, finalmente subversión en el mismo campo de las formas, lengua de mestizos. Sin embargo, la experiencia vienriana, reclama un tercer elemento el tratamiento de las lenguas nativas: para Adolfo Vienrich las lenguas vernáculas que explora suponen riqueza lingüística y las valora como elementos integrantes de la cultura nacional, más exactamente, el indio no es sólo una propuesta ideológica con consecuencias sociales, sino un sujeto desentrañable en su propia cultura:

esa lengua que describe la rapidez del vuelo de los pájaros, el canto de las aves, el murmullo del follaje, el fragor de una tormenta i hasta el rastro de la huella que deja en su tránsito el ser amado: de esa lengua cuyos acentos son de Job jen cuyos haraui sus poetas representan a las rocas quebrantándose por dapena, al pecho humanos deshaciéndose en lágrimas, ja la naturaleza entera conmoviéndose i simpatizando con las quejas i suspiros de un amante desdichado» (TPH: $\mathrm{XL}-\mathrm{XLI}$ ).

\section{Biblioteca de Letras}

\section{Militancia indigenista "Jorge Puccinelli Converso"}

El discurso de Adolfo Vienrich comporta militancia indigenista, por ello, reinvindica al indio, precisamente porque la realidad social de la época lo expolia y mezquina. Ésta tiene que ver con una «racionalidad» que considera al otro desde una visión que no lo incluye, incluso, como «humano», porque le resulta siempre exótico ${ }^{6}$. La expoliación y mezquindad de la que estoy hablando tienen que ver, pues, con otra operación que se produce en varios escritores de la época ante el hecho de la «inviabilidad» del Perú luego de la Guerra del Pacífico. Dicha operación se traduce en discurso solidario, se leen con la república del indio, desde donde elaboran y tentan la creación de un nuevo imaginario; de allí que reconocen a los indígenas como esenciales en la conforma-

- J. Sánchez Parga lo utiliza en el sentido de realidad "al extremo de lo distante y ajeno al observador " y "resulta ex-ótico al ser ex-traído o ex-cluído del contexto que lo hace significante." Cf. La observación. la memoria y la palabra en la imesrigación social (Quito, CAAP, 1989) p. 58 y ss. 
ción de la nueva imagen de país, y desde el plano de las adhesiones ideológicas, podríamos decir que Vienrich es, desde ya, panfletario y suficientemente indigenista, por lo que aflora en él una escritura inevitablemente antihispánica.

Esta adhesión opera como sentido de pertenencia: reconoce un escenario donde se configura la suerte del país por lo que se compromete como colecti$v^{7}{ }^{7}$. La función del «nosotros» identifica a todo el texto como la forma enunciativa propositiva que construye un lenguaje que vamos a llamar de proclama e imprecación. Es este lenguaje el que inaugura un discurso sobre la cultura y civilización del indio peruano. Por esa razón el sentido de un "yo» tácito casi desaparece en el texto: "nosotros que hemos vivido cerca...» «I si creen que nuestro entusiasmo nos mueve...» (TPH: XLII); «entre nosotros gran parte de las tradiciones i costumbres incáicas han desaparecido [...] donde quiera se investigue, se descubren las huellas del pasado" (TPH: XLIX); "veamos porque medios procuraban mantener vivo el recuerdo" (TPH: LI); «Como recuerdo de esos bailes nos quedan..., (TPH. LIV); etc. De manera que, el discurso vienriano se abre a una permanente invocación a sus lectores virtuales, para que su trabajo sea «luz» aunque «ébil contribución que todos los verdaderos peruanos debemos a nuestros antepasados» (TPH: IV). La óptica de Adolfo Vienrich se vuelve unatentación permanente por el testimonio y la empatía con la cultura de la repüblica del indio.

De otra parte, la büetlaiesctitura puede revelaela armonización lograda en el texto a través de la eqnersián delas̄ipetencialidades que ofrece la imagen de la choza:

Los años transcurren, pasan los siglos, pero el jenio nacional no muere: se refujia en las chozas. Adormecida la pujanza de la raza ya no hai grandiosos monumentos, ni soberbios caminos, ni acueductos; las filigranas de oro i plata la codicia las ha hecho desaparecer; los tejidos i los cántaros en el que el hilo i el barro rivalizan en finura i delicadeza de colorido i confección, ya no se ven; solo unas cuantas escenas de sus dramas que en el silencio de las punas representan; solo sus poemas, sus idilios i romances de amor el conquistador ya criollo, ya modificado por el medio, los conserva, asimilándose-

Manuel Valladares Quijano en su Aptmtes para uma biografía del stijeto colectivo_ (Lima, UNMSM - Escuela de Post Grado, Agosto 1993: Doctorado en Literatura 1993) recuerda que la construcción del sujeto, moderno y colectivo. está representado por la clase obrera, pero en países como América Latina esté se vincula a las fuerzas anti-oligarcas $y$ anti-imperialista. 
los; pero en la puerta de la choza está el abuelo que en las noches de luna, cuando velan, refiere las tradiciones de la raza. los cuentos i los apólogos que una exhuberante imajinación ha creado, i allí. hasta en sus distracciones las máximas de la más pura moral se ofrecen al niño i al joven: ora bajo la forma de apólogos llenos de gracia, observación y donosura; ora en juegos como el chupanta -paqui, el huin -huin, la paca-paca i otro más. (TPH: XLII; énfasis mío).

Esta llamada condensa la otra versión de la época: el indio está representado en metáfora de la choza. La choza no es el solar de la ciudad colonial, no es el espacio integrado a la civilización, a las normas del progreso; sin embargo, siendo pasado es simultáneamente presente y el presente se está imaginado acá como posibilidad. Y el indio se desestereotipa para incluirse, en esta versión de fines del XIX, como la "raza" marginada en la que descubre "máximas de la más pura moral». No es un sujetô a-histórico, cosificado; no es «raza inca» a secas, encara a este segmento social en el tiempo, con una historia; de cuya actualidad va referir en relacion al munder de la cultura y desde las diversas muestras que recoge (costumbres, saberes, juegos, poesía y relatos orales, esto es tradición oral y la propia lengua como fuente de un logro mayor de los indios). Dicha vigencia da sopotte al imaginario de país en que resuelve su propia crisis nuestro autor:

porque los paéblös ng-creen eñ su đestinosjino sobre la fé de sus antepasados i no edifican su poryenjr sinó con las piedras arrancadas á las tumbas de sus generaciones muertas. Vaya este párrafo como respuesta á aquellos que miran como utópico fundar el provenir nacional, sobre la base de la tradición incaica. (TPH: LXIV).

Imaginar el futuro significa acá un pie en la historia y otro en las posibilidades de futuro, dicha lectura sugiere que la historia se convierte en savia para generaciones venideras. La resolución del conflicto se armoniza en un doble escenario, colectivo e individual, en su opción por la república de indios. Y en relación a Adolfo Vienrich es la culminación de sus búsquedas en una adhesión que significa pertenencia, consciencia, por lo mismo actuación ante sujeto con historia, sujeto histórico al fin, a una colectividad que interpela desde su propia individualidad. 


\section{BIBLIOGRAFIA}

ANGELES CABALLERO, César A.

1957 «Adolfo Vienrich» en Dominical sup. de La Crónica. Lima, 15 setiembre de 1957; p. 4.

1988

Folklore peruano. Tomo I. Lima, 1988. (Edición auspiciada por CONCYTEC)

BARTHES, Roland

El susurro del lenguaje. Más allá de la palabra y de la escritura. Trad. de C. Fernández Medrano. Barcelona, Ed. Paidós, 1987 (Le bruissement de la langue, 1984).

CORNEJO POLAR, Antonio

1989

La formación de la tradición literaria en el Perú. Lima, Centro de Estudios y Publicaciones (CEP), 1989; 199 pp.

Corresponsal, El 1897

«Provincial Tarmaxal El Tiempô,Lim@, 5 julio 1897. [Despacho «delrge RedcinielldeCD897erSobre la muerte Adolfo Vienrich]

DIAZ SUAREZ, Plácido

1990 El Colegio Guadalupe y la Educación Peruana. Lima, Imp. Ed. Mantaro, 1990. $311 \mathrm{pp.}$

ESCAJADILLO G., Tomás

1995

La narrativa indigenista peruana. Lima, Amaru Editores, 1995. 333 pp.

ESPINO RELUCÉ, Gonzalo

1996

Adolfo Vienrich: La tentativa de la otra literatura peruana. Tesis para optar el grado de Magíster en Literatura Peruana y Latinoamericana. Lima, Universidad Nacional Mayor de San Marcos, Escuela de Post Grado, Facultad de Letras y Ciencias Humanas, diciembre, 1996. 
ESPINOSA BRAVO, Clodoaldo Alberto.

1967

El hombre de Junin frente a su paisaje y su folklore. Lima, Tall. Gráf. P.L Villanueva, 1967. t. I.

GAMARRA, Abelardo M. «El Tunante»

1921/1963 Cien años de vida perdularia. Lima, Casa de la Cultura del Perú, 1963.

1973 En la ciudad de Pelagatos. 2a. ed. Selección, prólogo y nota bio-bibliográfica de Edmundo Cornejo U. Lima, Peisa Ediciones, 1973 (Biblioteca Peruana, 46).

GARCILASO DE LA VEGA, Inca

1609/1985 Comentarios Reales de los Incas. Primera Parte. Prólogo de Aurelio Miró S.; bibliografía de Alberto Tauro y edición de César Pacheco Vélez. Lima, Banco de Crédito del Perú, 1985.

GONZALEZ PRADA, Manuel

1886 "Conferencia del Sr. Prada» en El Ateneo de Lima, t. I. Lima, 1886; pp. 29,47. [Al final: "Conferencia Literaria de 30 de Enero 86»].

1894 Pájinas libjes. Prólogo y notas de Luis Alberto Sánchez. Lima, Eds. COPECP985. (Q Obfas-1)aS

1908

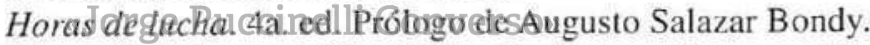
Lima, Ed. Universo, 1981. (Colección Autores Peruanos 42).

1935 Baladas peruanas. Prólogo de Luis Alberto Sánchez. Santiago de Chile, Ed. Ercilla, 1935. 2a. Lima, Biblioteca Universitaria, 1966. 3ra. ed. Lima, Lib. Bendezú, 1969. También en Obras de Manuel González Prada, Prólogo y notas de Luis Alberto Sánchez Lima, Ed. COPE, 1988, tomo III, vol. 5; pp. 387-468.

1969 Figuras y figurones. Lima, Lib. Bendezú, 1969.

MARIATEGUI, José Carlos

1928

7 ensayos de interpretación de la realidad peruana. 5a. ed. Lima, Emp. Ed. Amauta, 1988. (Obras completas/ Biblioteca Amauta 2). 
MARX, Carlos y ENGELS, Federico

1968

Sobre arte y literatura. Introducción, selección y notas de

Valeriano Bozal. Fernández. Madrid, Ed. Ciencia Nueva, 1968.

NORIEGA BERNUY, Julio

1993

Poesía quechua escrita en el Perí. Antología. Lima, CEP, 1993.

PUCCINELLI, Jorge

1945

"Adolfo Vienrich, precursor del folklore peruano» en Mercurio Peruano Año XX, vol. XXVI, No. 216. Lima, marzo 1945; pp. [130]-135.

REYES, Alfonso

1952

La experiencia literaria.3ra. ed. Buenos Aires, Ed. Losada, 1969.

TORERO, Alfredo

1974

El quechua y la historia social andina. Lima, Universidad Ricardo Palma, 1974.

VARIOS

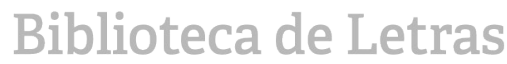

1908

Corona finebre. Tarma, Imp. Eas Aurora de Tarma, 1908. (Dedicada a Adolfo Vienrich)

VIENRICH, Adolfo

1888

Aliso peruano. Lima, «La Gaceta Científica», 1888.(Ver: La Gaceta Científica, t. IV: No. 9 Lima, 30 junio 1888; pp. 235240; No.10 Lima, 31 julio 1888; pp. 265-269; y, No. 11 Lima 31 agosto 1888; pp. 300-301. Luego del título: «Tesis leída por Adolfo D. Vienrich al optar el grado de Bachiller en la Facultad de Ciencias de la Universidad Mayor de San

1904 Marcos de Lima - 1888». Al final: «Marzo 18 de 1888».) Silabario tarmeño. Método analítico-sintético. De lectura, escritura, ortografía i elocuencia. Tarma, Imp. La Aurora de Tarma, 1904; 136 pp. (Biblioteca «Aurora») 
Tarmap Pacha-Huaray/ Azucenas Quechuas (Nuna-shimi chihuanhaui). Bilingüe. Tarma, Imp. La Aurora de Tarma, 1905; CXXIV, 131 pp. (Antes del título: Tarmap PachaHuaray. Al final del Prólogo: Pumacahua/ Tarma, 27 de Octubre de 1905). 2da. ed. Nota preliminar de Pedro Díaz Ortiz. Tarma, Consejo Provincial de Tarma, 1956; 109 pp. 3ra. ed. «Nota preliminar» de Pedro Díaz Ortiz. Huancayo, Casa de la Cultura de Junín, s/a. 109 pp. (Biblioteca Huanca 2).

1906 Tarmapap Pachahuarainin/Fábulas Quechuas. Tarma, Tip. La Aurora de Tarma, MDCCCCVI (1906), 65 pp. 2da.ed. Lima, Ed. Lux, 1961; 79 pp. (Serie Difusión del Libro del Centro No. 1). 3a. ed. Prol. Víctor Soracel. Lima, Instituto de Apoyo Agrario - Eds. Rikchay Perú, 1989; 84 pp. (Cultura Andina 1).

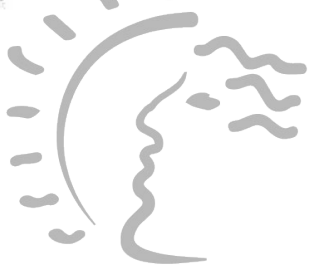

Biblioteca de Letras "Jorge Puccinelli Converso» 